\title{
Preparation and stress-strain behavior of in-situ epoxidized natural rubber/SiO 2 hybrid through a sol-gel method
}

\author{
S. M. Li ${ }^{1}$, T. W. Xu' ${ }^{1}$ Z. X. Jia ${ }^{1 *}$, B. C. Zhong ${ }^{1}$, Y. F. Luo ${ }^{1}$, D. M. Jia ${ }^{1}$, Z. Peng ${ }^{2}$ \\ ${ }^{1}$ College of Materials Science and Engineering, South China University of Technology, 510640 Guangzhou, China \\ ${ }^{2}$ Agricultural Product Processing Research Institute, Chinese Academy of Tropical Agriculture Sciences, 524001 \\ Zhanjiang, China
}

Received 4 August 2017; accepted in revised form 4 October 2017

\begin{abstract}
In this paper, epoxidized natural rubber was reinforced by silica generated in-situ though the sol-gel method using tetraethoxysilane(TEOS) as precursor. The results showed that the ring opening reaction of epoxy group appeared in the insitu reaction progress, where the hydrogen bond between $\mathrm{Si}-\mathrm{OH}$ and $\mathrm{C}-\mathrm{OH}$ was mainly formed to enhance the stress-strain behavior of ESH simultaneously. During the hot pressing progress, the compound was crosslinked via the chemical reaction of $\mathrm{Si}-\mathrm{OH}$ and $\mathrm{C}-\mathrm{OH}$. The chemical bond between $\mathrm{Si}-\mathrm{OH}$ and $\mathrm{C}-\mathrm{OH}$ reinforced rubber-filler interaction, resulting further improved the stress-strain behavior. Besides, comparing with precipitated $\mathrm{SiO}_{2}$ filled ENR, the dispersion of $\mathrm{SiO}_{2}$ in $\mathrm{ENR}$ matrix was distinctly more uniform though the sol-gel method, along with the enhancement of mechanical properties. Herein, our findings open up a new way to prepare an environmentally friendly rubber composite with excellent dispersion and strong rubber-filler interaction without curing agent effectively.
\end{abstract}

Keywords: rubber, $\mathrm{ENR} / \mathrm{SiO}_{2}$ hybrid, sol-gel reaction, interaction

\section{Introduction}

Epoxidized natural rubber (ENR) is derived from the partial epoxidation of the natural rubber possessing some new properties such as good wet grip, oil resistance, excellent flexibility and low rolling resistance $[1,2]$. The epoxy group of ENR is unstable that could be utilized for the modification of ENR or being a compatilizer $[3,4]$ in rubber composites. It is well known that $\mathrm{SiO}_{2}$ is used widely in industry except for carbon black, usually as a reinforcement agent or a functionalized filler to impart specific properties for rubber compounds [5]. In our previous work, The $\mathrm{ENR} / \mathrm{SiO}_{2}$ hybrids prepared by an openmill mixing method had been reported, and the interfacial interaction of ENR and $\mathrm{SiO}_{2}$ was investigated. The results indicated that the ring-opening reaction of the epoxy groups of ENR chains occurs and the covalent bonds between $\mathrm{C}-\mathrm{OH}$ of ENR and
$\mathrm{Si}-\mathrm{OH}$ groups on the silica surfaces were formed, which can improve the dispersion of silica in the rubber matrix and enhance the interfacial combination between rubber and silica. However, the hybrid obtained a good strength only with a high content of $\mathrm{SiO}_{2}$ [6], where the elongation at break of hybrid was limited regrettably. This might be attributed to the insufficient filler-rubber interactions. There are still improvements that need to be made in the elongation at break and processability.

Mark and Pan [7] firstly proposed a new approach for preparing silica-filled elastomers by generating the silica particles inside the crosslinked silicone rubber. The sol-gel process brings a good dispersion of the silica filling into the rubbery matrix. In general, the sol-gel reaction of tetraethoxysilane (TEOS) takes place easily and proceeds in the two steps, hydrolysis and condensation reactions, to produce $\mathrm{SiO}_{2}$. 
To obtain a preferable interfacial interaction between polymer matrix and $\mathrm{SiO}_{2}[8]$, in-situ synthesis method was widely used to to reinforce polymers like natural rubber [9], NR latex [10], natural rubber grafted by methyl methacrylate [11] and SBR. The contact probability between hydroxyl of in-situ $\mathrm{SiO}_{2}$ and rubber matrix was increased via an in-situ approach that is beneficial to the improvement of rubber-filler interaction.

There are several articles about in-situ $\mathrm{SiO}_{2}$ reinforced ENR composites [12-14], which achieved high mechanical property improvements with the assistance of dicumyl peroxide (DCP) [13], benzoyl peroxide $(\mathrm{BzO})[14]$ as the crosslinking agents. DCP crosslinked composites ENR exhibit higher tensile strength and modulus (almost 60 and 20\% respectively) than those of the uncured composites, which showed better performance compared to $\mathrm{BzO}$ crosslinked system. Unfortunately, these low-molecularweight assistants possess disadvantages of migration, volatility, and color contamination.

With the purpose of overcoming the drawbacks of crosslinking agent, we explored a novel preparation method of self-crosslinkable ENR filled with in-situ $\mathrm{SiO}_{2}$.

In this article, an in-situ $\mathrm{ENR} / \mathrm{SiO}_{2}$ hybrid (ESH) was prepared though sol-gel method and self-crosslinked via the interaction of open-loop ENR and $\mathrm{SiO}_{2}$ after hot-pressing process. Fourier Transform Infrared (FTIR), Thermogravimetric Analysis (TGA), Differential Scanning Calorimetry (DSC) and contact angle measurement were used to characterize the structure changes of ESH. The morphology of ESH was also investigated. Additionally, mechanical properties of the hybrid were compared with that of precipitated
$\mathrm{SiO}_{2}$ filled ENR compounds. The results indicated that the sol-gel method did a positive effect on the enhancement of $\mathrm{ENR}-\mathrm{SiO}_{2}$ interface interactions.

\section{Experimental}

\subsection{Materials}

Epoxidized natural rubber (ENR50, with $50 \mathrm{~mol} \%$ of epoxy content) was kindly supplied by the Agricultural Product Processing Research Institute, Chinese Academy of Tropical Agriculture Sciences (Zhanjiang, China). Precipitated $\mathrm{SiO}_{2}$ (type 518) was provided by the Wanzai Huiming Chemical Limited Co. (Jiangxi, China). Tetraethoxysilane (TEOS), tetrahydrofurane (THF) and hydrochloric acid $(\mathrm{HCl})$ were analytical reagents and used as received.

\subsection{Preparation of ESH}

Epoxidized natural rubber (ENR, $9 \mathrm{~g}$ ) was dissolved in tetrahydrofurane (THF, $300 \mathrm{~mL}$ ) at room temperature until homogeneous phase was obtained via the treatment of stirring for $30 \mathrm{~min}$. Subsequently, tetraethyl orthosilicate (TEOS, $4.5 \mathrm{~g}$ ) and deionized water $(9 \mathrm{~g})$ were added into the solvated rubber under stirring for $50 \mathrm{~min}$ to generate $\mathrm{SiO}_{2}$ though sol-gel method. $\mathrm{HCl}$ was used to maintain the reaction $\mathrm{pH}$ at 1.5. The obtained in-situ $\mathrm{SiO}_{2}$ filled ENR matrix was poured into a watch glass and dried for $24 \mathrm{~h}$ at room temperature. Then the product was dried in a vacuum oven $\left(50^{\circ} \mathrm{C}\right)$ for $48 \mathrm{~h}$ until the sample weight became constant. The in-situ $\mathrm{SiO}_{2}$ rubber compound were made into the sheets by flat vulcanizing machine at $60^{\circ} \mathrm{C}, 145^{\circ} \mathrm{C}$ for $20 \mathrm{~min}$, which were called ESH-1, ESH-2, respectively. Figure 1 sketches the synthetic procedure. For preparing the reference sample ESH3, precipitated $\mathrm{SiO}_{2}$ (type 518) was directly added

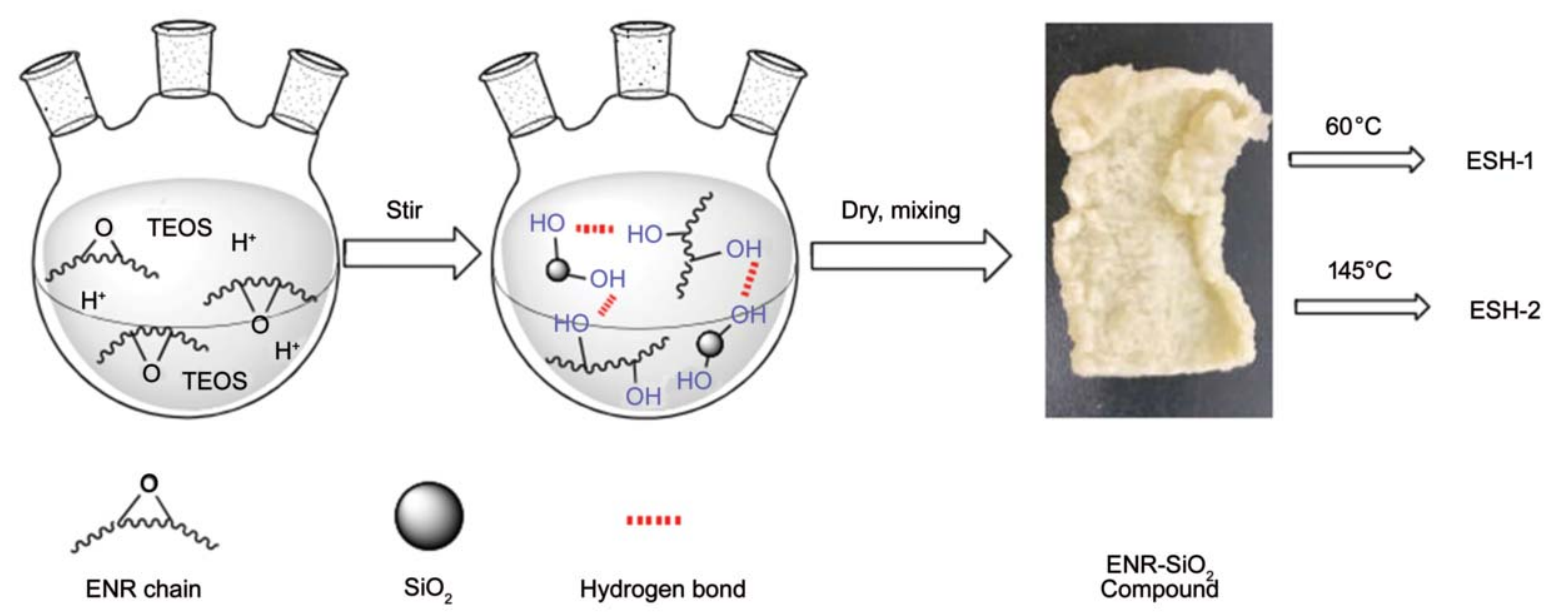

Figure 1. Synthetic procedure of ESH 
into dissolved ENR. The suspension was well blended and dried as per the in-situ $\mathrm{SiO}_{2}$ rubber compound detailed above. And the ENR-SiO 2 compound was made into the sheets by flat vulcanizing machine at $145^{\circ} \mathrm{C}$ for $20 \mathrm{~min}$. The additive amount of precipitated $\mathrm{SiO}_{2}$ was according to the residual weight of ESH2 in the TGA test, which was $17 \%$ approximately.

\subsection{Characterization}

FTIR spectra of ESH were recorded with a Bruker Vector 70 FTIR spectrometer in the range of 4000 to $400 \mathrm{~cm}^{-1}$. TGA was executed using a NETZSCH TG $209 \mathrm{~F} 1$ in the range of $35 \sim 700^{\circ} \mathrm{C}$ under nitrogen at a heating rate of $20^{\circ} \mathrm{C} / \mathrm{min}$. DSC was conducted with a NETZSCH DSC 204 F1 under nitrogen atmosphere. The temperature program involved $2 \mathrm{~min}$ isothermal hold at $50^{\circ} \mathrm{C}$ followed by heating at $10^{\circ} \mathrm{C} / \mathrm{min}$ to $250^{\circ} \mathrm{C}$ under nitrogen. The water contact angles (WCAs) were measured with a goniometer (KRÜSS DSA 100, Germany) using liquid droplets of $4 \mu \mathrm{L}$ in volume. The morphology of the ESHs were obtained with a Zeiss Merlin SEM machine (Germany) at an acceleration voltage of $5 \mathrm{kV}$. The samples were immersed into liquid nitrogen to make brittle fracture sections. The fracture surface was sprayed with gold before testing. The stress-strain behaviors of ESH were carried out with a UCAN UT-2060 instrument according to ISO 37-2005 standard (dumbbell A shape), and five samples were selected for one parameter representation.

\section{Results and discussion}

Figure 2 shows the FTIR spectra of ENR, ESH-1, ESH-2, ESH-3 and $\mathrm{SiO}_{2}$. The peaks at 876 and $1250 \mathrm{~cm}^{-1}$ of ENR are attributed to the stretching and deformation vibration of epoxy group [15]. The peaks

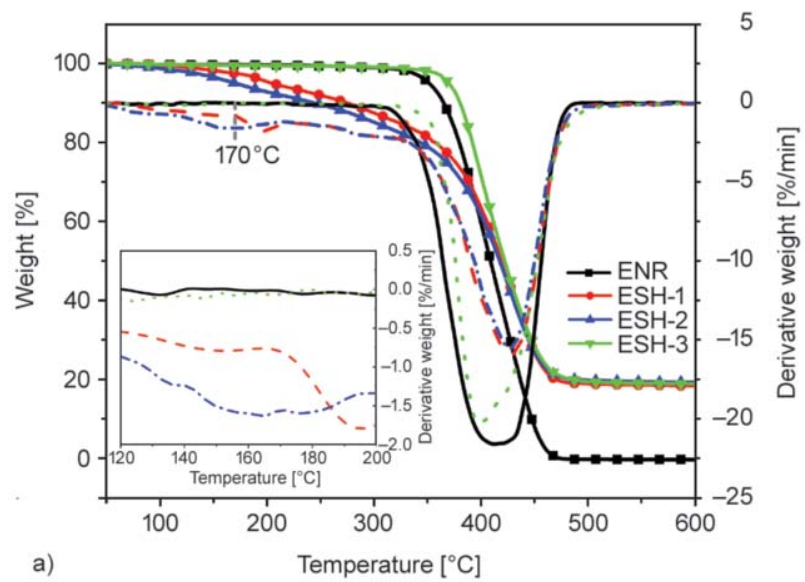

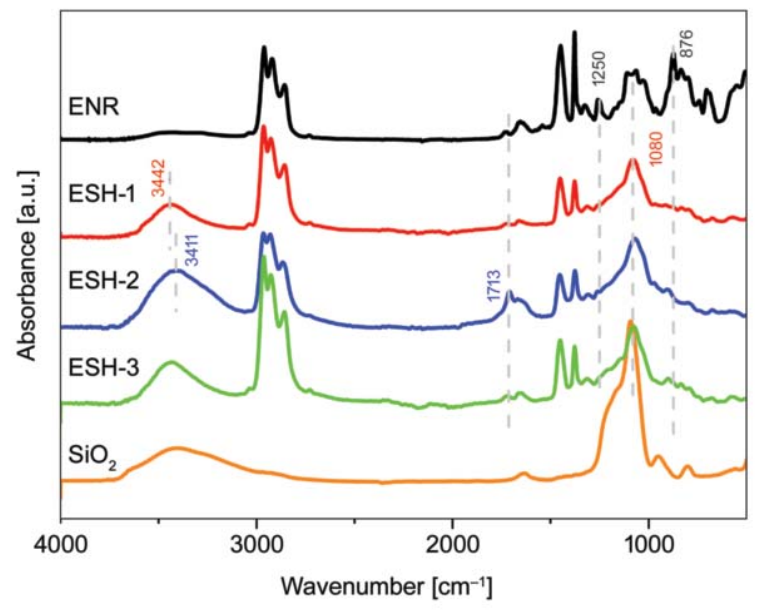

Figure 2. FTIR spectra of ENR, ESH-1, ESH-2, ESH-3 and $\mathrm{SiO}_{2}$

at $3409,1080 \mathrm{~cm}^{-1}$ of $\mathrm{SiO}_{2}$ represents the stretching vibration of $\mathrm{Si}-\mathrm{OH}$ and $\mathrm{Si}-\mathrm{O}-\mathrm{Si}$. It can be seen that 876 and $1250 \mathrm{~cm}^{-1}$ disappear in the spectrum of ESH-1, simultaneously a new peak at $3446 \mathrm{~cm}^{-1}$ standing for the stretching vibration of hydroxyl appears which indicates the acid catalyzed ring opening reaction of the epoxy group that formed the alcohol hydroxyl. Besides, The ratio of $-\mathrm{OH} / \mathrm{Si}-\mathrm{O}-\mathrm{Si}$ stretching vibration is increased from $\mathrm{SiO}_{2}$ to ESH-1 demonstrating the new hydroxyl was generated. Comparing with the spectrum of ESH-1, a new peak at $1713 \mathrm{~cm}^{-1}$ shows up owing to the stretching vibration of $-\mathrm{C}=\mathrm{O}$ in $\mathrm{ESH}-2$, which was introduced by the oxidation of $\mathrm{C}-\mathrm{OH}$ under hot-press treatment at $145^{\circ} \mathrm{C}$. Meanwhile, the increase of intensity and red shift of hydroxyl absorption peak from 3442 to $3411 \mathrm{~cm}^{-1}$ imply the stronger hydrogen-bond interaction between $-\mathrm{C}=\mathrm{O} /-\mathrm{OH}$ than that of $-\mathrm{OH} /-\mathrm{OH}$.

TGA and DTGA curves of ENR, ESH-1, ESH-2 and ESH-3 are depicted in Figure 3a, respectively and

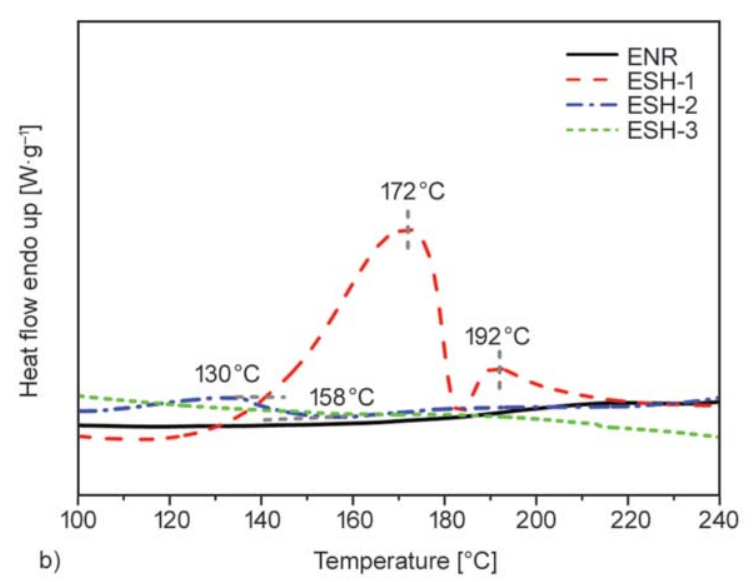

Figure 3. a) TGA and b) DSC curves of ENR, ESH-1 and ESH-2 


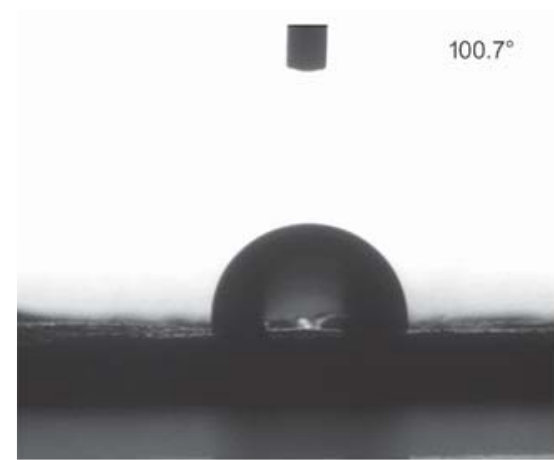

$100.7^{\circ}$

a)

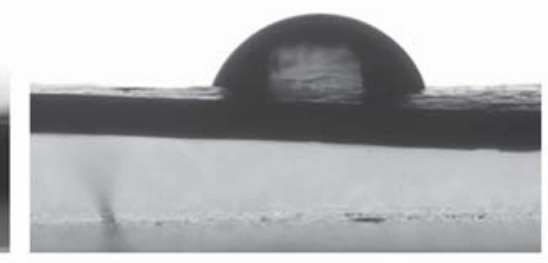

b) $73.9^{\circ}$

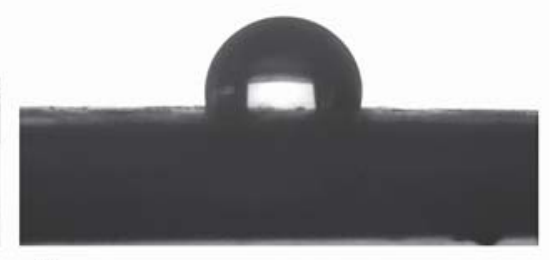

c)

Figure 4. The contact angle of a) ESH-1, b) ESH-2 and c) ESH-3

the DSC plots are shown in Figure 3b. It was observed that the initial degradation temperature of ESH-1 and ESH-2 both shift to a lower value comparing with ENR, which means a decrease of thermal stability for hybrid that is in line with our previous work. Simultaneously, there is an obvious difference between ESH-1 and ESH-2 obtained from the DTG curves in the range of $120 \sim 200^{\circ} \mathrm{C}$. A rapid decline arises around $170^{\circ} \mathrm{C}$ for $\mathrm{ESH}-1$ while a similar phenomenon shows up around $120^{\circ} \mathrm{C}$ for $\mathrm{ESH}-2$. The former is related to the volatilization of water generated from the chemical reaction between $\mathrm{Si}-\mathrm{OH}$ and $\mathrm{C}-\mathrm{OH}$, where an endothermal effect had been detected at $172{ }^{\circ} \mathrm{C}$ peak by DSC in Figure $3 \mathrm{~b}$. The latter reflects the volatilization of absorbed water, which was absorbed on the sample's surface by the generated polar $-\mathrm{C}=\mathrm{O}$ group that formed a strong hydrogen-bond interaction with hydroxyl of $\mathrm{H}_{2} \mathrm{O}$. This could also be proved through an exothermic effect that presents among $130 \sim 160^{\circ} \mathrm{C}$ by DSC in Figure $3 \mathrm{~b}$ caused by the destruction of hydrogen-bond interaction. The endothermal peak of ESH- 1 around $192^{\circ} \mathrm{C}$ by DSC might be caused by the oxidation of $\mathrm{C}-\mathrm{OH}$ to $-\mathrm{C}=\mathrm{O}$, which could be confirmed in FTIR spectra. There are no endothermal peaks arise in ESH-2 curve indicating

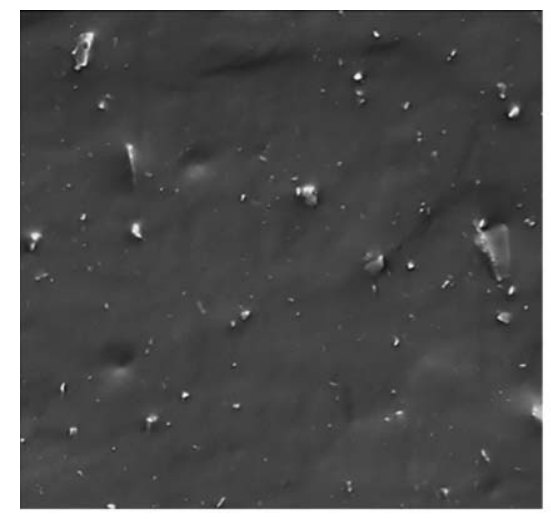

a)

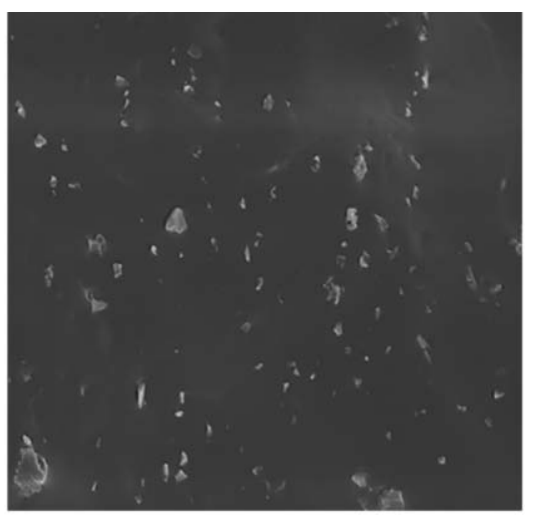

b) the chemical reaction between $\mathrm{Si}-\mathrm{OH} / \mathrm{C}-\mathrm{OH}$ and oxidation of $\mathrm{C}-\mathrm{OH}$ had been finished in the hot press process. Actually, the hot press temperature $\left(145^{\circ} \mathrm{C}\right)$ is different from the DSC result that is due to the impact of pressure. TGA and DSC curves of ESH-3 show no much differences with ENR.

To illustrate the hydrophilic character of ESH, the contact angle measurement was employed and the result is described in Figure 4. As it can be seen the contact angle of ESH-1, ESH-2 are 100.7, 73.9 ${ }^{\circ}$, respectively. That means a better hydrophilicity for ESH-2 comparing with ESH-1. Thus, a stronger interaction between ESH-2 and water is confirmed caused by the effect of polar $-\mathrm{C}=\mathrm{O}$ group. The consequence sustains the deduction of the volatilization of absorbed water for ESH-2 in TGA curve. The contact angle of ESH-3 is a little bigger than that of ESH1 , which means their surface features are similar. To investigate the morphology of the hybrids, SEM measurements were employed to view the morphology of cryofracture surfaces in Figure 5. In the SEM images of ESH-1 and ESH-2, $\mathrm{SiO}_{2}$ particles were scattered uniformly throughout the hybrid. On the contrary, large aggregates and agglomerates can be seen in the ENR matrix for ESH-3. The better dispersion

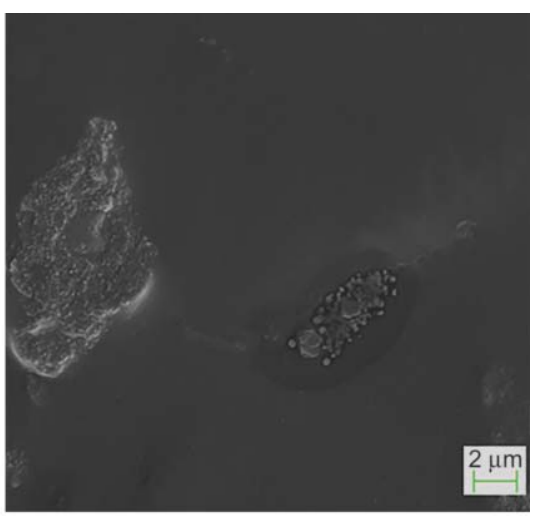

c)

Figure 5. SEM images of a) ESH-1, b) ESH-2, c) ESH-3. 

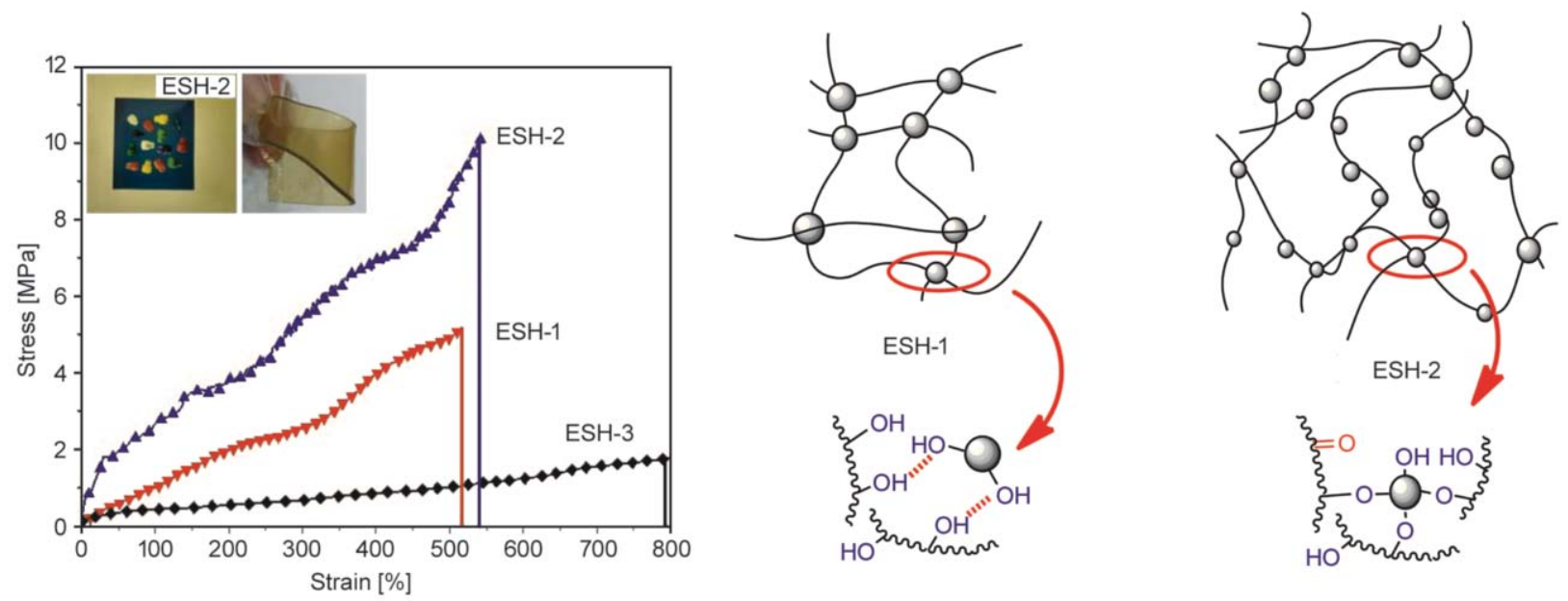

Figure 6. The stress-strain curves of ESH-1, ESH-2, ESH-3 and its interaction diagrams

of in-situ $\mathrm{SiO}_{2}$ in ENR matrix by the sol-gel method of ESH-2 would be expected to result in the superior mechanical properties than ESH-3, which is addressed in the next section.

Figure 6 illustrates the stress-strain behaviors of ESH1, ESH-2 and ESH-3. Comparing with the curve of ESH-3, the modulus and strength of ESH-1 are improved significantly, which indicates a stronger hydrogen-bond interaction exists in ESH-1 than in the case of the traditional mechanical mixing method. This is because the excellent dispersion of $\mathrm{SiO}_{2}$ in ENR matrix via in-situ reaction way leading to a stronger rubber-filler hydrogen-bond interaction, supporting by the morphology of the hybrids. The schematic can be seen in Figure 7. After the hot press treatment in $145^{\circ} \mathrm{C}, \mathrm{ESH}-2$ gains a higher modulus or strength than ESH-1, as well as a good elongation at break. According to our previous works, this depends on the chemical bond between $\mathrm{CH}_{3}-\mathrm{C}-\mathrm{OH}$ and $\mathrm{Si}-\mathrm{OH}$ generated during the hot press process at $145^{\circ} \mathrm{C}$ for $20 \mathrm{~min}$. Thus, $\mathrm{SiO}_{2}$ served as both self-vulcanizing agent and reinforcing agent in ESH matrix.

\section{Conclusions}

In summary, in-situ epoxidized natural rubber/ $/ \mathrm{SiO}_{2}$ hybrid was prepared though the sol-gel method where $\mathrm{SiO}_{2}$ acted as self-vulcanizing agent and reinforcing agent without any curing additives. The results showed that the ring opening reaction of epoxy group happened during the in-situ reaction process, where hydrogen-bond interaction among $\mathrm{OH}$ was formed to enhance mechanical properties of ESH. Besides, the chemical bond between $\mathrm{Si}-\mathrm{OH}$ and $\mathrm{C}-\mathrm{OH}$ and $-\mathrm{C}=\mathrm{O}$ groups were generated during the hot press process, which reinforces rubber-filler interaction and promotes the mechanical properties of ESH significantly. The sol-gel method gained a more uniformly dispersion of $\mathrm{SiO}_{2}$ in ENR matrix by comparing precipitated $\mathrm{SiO}_{2}$ filled ENR. Therefore, the in-situ method provides a new opportunity to prepare the environmental friendly rubber composite effectively with excellent dispersion and strong rubber-filler interaction without curing agent effectively.

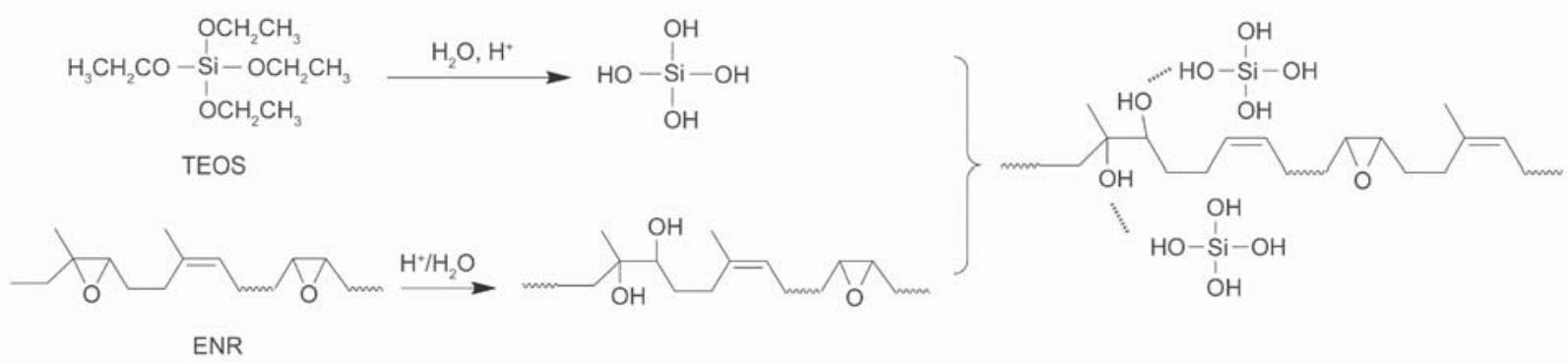

Figure 7. Hydrogen bond interaction between $\mathrm{ENR}$ and $\mathrm{SiO}_{2}$ in sol-gel reaction process 


\section{Acknowledgements}

This work was supported by the National Basic Research Program of China [grant numbers 2015CB654700 (2015CB674703)]; the Special Fund for Agro-scientific Research in the Public Interest from the Ministry of Agriculture, China [grant number 201403066]; National Natural Science Foundation of China [grant number 51573051] and the National Key Technology R \& D Program of China [grant number 2012BAE01B03]; Fundamental Research Funds for the Central Universities (2017BQ033) and China Postdoctoral Science Foundation (2017M612658); We are grateful to the China Scholarship Council for its support.

\section{References}

[1] Hamzah R., Bakar M. A., Dahham O. S., Zulkepli N. N., Dahham S. S.: A structural study of epoxidized natural rubber (ENR-50) ring opening under mild acidic condition. Journal of Applied Polymer Science, 133, 44123/1-44123/13 (2016).

https://doi.org/10.1002/app.44123

[2] Soheilmoghaddam M., Wahit M. U., Akos N. I.: Regenerated cellulose/epoxidized natural rubber blend film. Materials Letters, 111, 221-224 (2013).

https://doi.org/10.1016/j.matlet.2013.08.109

[3] Xu T., Jia Z., Luo Y., Jia D., Zheng P.: Interfacial interaction between the epoxidized natural rubber and silica in natural rubber/silica composites. Applied Surface Science, 328, 306-313 (2015).

https://doi.org/10.1016/j.apsusc.2014.12.029

[4] Xu T., Jia Z., Li J., Luo Y., Jia D., Peng Z.: Study on the dispersion of carbon black/silica in SBR/BR composites and its properties by adding epoxidized natural rubber as a compatilizer. Polymer Composites, in press (2016).

https://doi.org/10.1002/pc.23946

[5] Manoharan P., Naskar K.: Exploring a highly dispersible silica-elastomer composite for tire applications. Journal of Applied Polymer Science, 133, 43531/1-43531/10 (2016). https://doi.org/10.1002/app.43531

[6] Xu T., Jia Z., Wang S., Chen Y., Luo Y., Jia D., Peng Z.: Self-crosslinkable epoxidized natural rubber-silica hybrids. Journal of Applied Polymer Science, 134, 44605/1-44605/10 (2017).

https://doi.org/10.1002/app.44605
[7] Mark J. E., Pan S-J.: Reinforcement of polydimethylsiloxane networks by in-situ precipitation of silica: A new method for preparation of filled elastomers. Macromolecular Rapid Communications, 3, 681-685 (1982). https://doi.org/10.1002/marc.1982.030031006

[8] Ikeda Y., Kameda Y.: Preparation of 'green' composites by the sol-gel process: In situ silica filled natural rubber. Journal of Sol-Gel Science and Technology, 31, 137142 (2004).

https://doi.org/10.1023/B:JSST.0000047975.48812.1b

[9] Poompradub S., Thirakulrati M., Prasassarakich P.: In situ generated silica in natural rubber latex via the solgel technique and properties of the silica rubber composites. Materials Chemistry and Physics, 144, 122-131 (2014).

https://doi.org/10.1016/j.matchemphys.2013.12.030

[10] Miloskovska E., Nies E., Hristova-Bogaerds D., van Duin M., de With G.: Influence of reaction parameters on the structure of in situ rubber/silica compounds synthesized via sol-gel reaction. Journal of Polymer Science Part B Polymer Physics, 52, 967-978 (2014).

https://doi.org/10.1002/polb.23516

[11] Watcharakul N., Poompradub S., Prasassarakich P.: In situ silica reinforcement of methyl methacrylate grafted natural rubber by sol-gel process. Journal of Sol-Gel Science and Technology, 58, 407-418 (2011). https://doi.org/10.1007/s10971-011-2407-x

[12] Hashim A. S., Kohjiya S., Ikeda Y.: Moisture cure and in-situ silica reinforcement of epoxidized natural rubber. Polymer International, 38, 111-117 (1995).

https://doi.org/10.1002/pi.1995.210380202

[13] Bandyopadhyay A., Sarkar M. D., Bhowmick A. K.: Epoxidized natural rubber/silica nanoscale organic-inorganic hybrid composites prepared by sol-gel technique. Rubber Chemistry and Technology, 77, 830-846 (2004). https://doi.org/10.5254/1.3547854

[14] Bandyopadhyay A., Sarkar M. D., Bhowmick A. K.: Epoxidised natural rubber/silica hybrid nanocomposites by sol-gel technique: Effect of reactants on the structure and the properties. Journal of Materials Science, 40, 53-62 (2005).

https://doi.org/10.1007/s10853-005-5687-0

[15] Xu H., Liu J., Fang L., Wu C.: In situ grafting onto silica surface with epoxidized natural rubber via solid state method. Journal of Macromolecular Science Part B, Physics, 46, 693-703 (2007). https://doi.org/10.1080/00222340701388854 